\title{
S100A8 and S100A9 Are Induced by Decreased Hydration in the Epidermis and Promote Fibroblast Activation and Fibrosis in the Dermis
}

Aimei Zhong, ${ }^{* \dagger}$ Wei Xu, ${ }^{*}$ Jingling Zhao, ${ }^{*}$ Ping Xie, ${ }^{*}$ Shengxian Jia, ${ }^{*}$ Jiaming Sun, ${ }^{\dagger}$ Robert D. Galiano, ${ }^{*}$ Thomas A. Mustoe, ${ }^{*}$ and Seok J. Hong*

From the Laboratory for Wound Repair and Regenerative Surgery, * Department of Surgery, Plastic Surgery Division, Northwestern University, Feinberg School of Medicine, Chicago, Illinois; the Department of Plastic Surgery, ${ }^{\dagger}$ Union Hospital, Tongji Medical College, Huazhong University of Science and Technology, Wuhan, China; and the Department of Burns, ${ }^{\ddagger}$ The First Affiliated Hospital of Sun Yat-sen University, Guangzhou, China

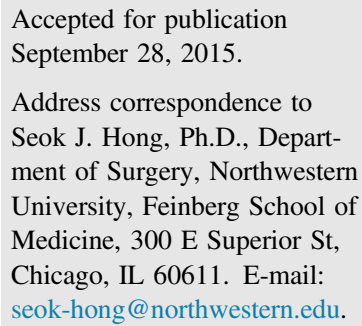

\begin{abstract}
The most critical function of the epidermis is to prevent water loss and maintain skin homeostasis. Disruption of the functional skin barrier causes delayed wound healing, hypertrophic scarring, and many skin diseases. Herein, we show that reduced hydration increases the expression of S100 protein family members, S100A8/S100A9, in stratified keratinocyte culture and human ex vivo skin culture. Immunohistological analyses show that S100A8/A9 are highly expressed in the epidermis of human hypertrophic scar and keloid tissues. Reduced hydration demonstrates activation of fibroblasts in the keratinocyte-fibroblast co-culture. In contrast, knockdown of S100A8 or S100A9 by RNA interference in keratinocytes failed to activate fibroblasts. Pretreatment with pharmacological blockers of S100A8/ A9 receptors, Toll-like receptor 4 and receptor for advanced glycation end products, inhibits fibroblast activation induced by recombinant S100A8/A9 proteins. Moreover, we observe that local delivery of S100A8 protein results in a marked increase in hypertrophic scarring in the in vivo rabbit ear scar model. Our results indicate that hydration status promotes fibroblast activation and fibrosis by directly affecting the expression of inflammatory signaling in keratinocytes, thereby strongly suggesting S100A8/A9 to be novel targets in preventing scarring. (Am J Pathol 2016, 186: 109-122; http:// dx.doi.org/10.1016/j.ajpath.2015.09.005)
\end{abstract}

Scarring is an inevitable result of the wound healing process. However, excess fibrosis results in hypertrophic scarring, causing cosmetic disfiguration and disruption of the skin barrier function. Hypertrophic scarring is commonly associated with a state of chronic inflammation caused by a variety of stimuli, including persistent tension, foreign body retention, and infection. The sustained release of many proinflammatory cytokines and chemokines, which contributes to the activation of fibroblasts and the excessive production of collagen in the dermis, is found in hypertrophic scars. ${ }^{1,2}$ Although scarring has been characterized as fibroblast activation in the dermis, recent evidence suggests that keratinocytes in the epidermis also play an essential role in this process. ${ }^{3-5}$

Unrecovered barrier function of the epidermis results in increased transepithelial water loss (TEWL) after wound repair in the skin. Many reports suggest that TEWL remains high in pathological scars, such as hypertrophic scars and keloids, and demonstrates that TEWL is implicated in dermal fibrosis after wounds are healed. ${ }^{6}$ It has been widely accepted that occlusion improves the appearance and symptoms of scars by regulating cytokines and growth factors in the epidermis. ${ }^{5,7,8}$ However, the mechanisms are not well charted yet. It is also known that mucosal wounds heal faster and have less scarring compared with skin

Supported by the Division of Plastic and Reconstructive Surgery, Northwestern University, Feinberg School of Medicine, internal funding, the Chinese Scholarship Council to work in Northwestern University for 2 years while performing this project (C.S.C.), and International Program of Project 985, Sun Yat-Sen University (J.Z.).

A.Z. and W.X. contributed equally to this work.

Disclosures: None declared. 
wounds, perhaps, in part, because of the moist characteristics of mucosal surfaces. ${ }^{9-11}$ By using the rabbit partialthickness incisional wounding scar model, we reveal that maintaining hydration enhances the wound repair process and down-regulates the expression of many cytokines compared with wounds in which hydration is not maintained. Interestingly, the global gene expression of skin wounds is also changed compared with that of mucosal wounds when hydration of the skin wounds is preserved. ${ }^{12}$

The expression of S100A8/A9 is significantly elevated in the epidermis when the skin is exposed to reduced hydration conditions. The low-molecular-weight proteins S100A8/A9 belong to the S100 protein family and are involved in diverse cellular processes, such as cell cycle regulation and differentiation. ${ }^{13-15}$ S100A8/A9 are abundantly expressed in myeloid cells and have been extensively characterized as major players involved in both acute and chronic inflammation. ${ }^{16-18}$ S100A8/A9 (alias calprotectin) have antifungal, antibacterial, and immunomodulating effects reflecting their protective properties. ${ }^{15,19,20}$ Interestingly, their expression is up-regulated in skin injury and during the wound healing process. ${ }^{21,22}$ Moreover, higher expression of S100A8/ A9 is found in cancer, intestinal diseases, and lesions of psoriasis patients. ${ }^{23}$ Herein, we hypothesize that decreased hydration (ie, increased TEWL) up-regulates proinflammatory cytokine expression, which further causes fibrosis in the dermis. In this study, we used human ex vivo skin culture (HESC) and stratified keratinocyte culture (SKC) to show that decreased hydration leads to up-regulation of S100A8/A9 in the epidermis. We then establish that S100A8/A9 from epidermal keratinocytes regulate dermal fibroblast activation through Toll-like receptor 4 (TLR4) and receptor for advanced glycation end products (RAGE) with the loss-of-function study using RNA interference (RNAi) and gain-of-function study using recombinant proteins. Finally, we demonstrate that delivery of exogenous S100A8 protein causes increased hypertrophic scar formation in the rabbit ear model.

\section{Materials and Methods}

\section{HESC and SKC}

HESC was performed following the protocol described previously. ${ }^{24}$ Briefly, skin from elective abdominoplasties was processed to make partial-thickness skin grafts that were cultured in growth medium: Dulbecco's modified Eagle's medium (DMEM) supplemented with 10\% fetal bovine serum (FBS) and penicillin-streptomycin (Life Technologies, Grand Island, NY). The stratum corneum of the skin was removed by tape stripping to remove the functional skin barrier.

SKC was performed following the standard protocol..$^{25,26}$ $\mathrm{HaCaT}$ cells, a spontaneously immortalized human keratinocyte cell line, were cultured in DMEM containing 10\% FBS. Human primary foreskin keratinocytes were obtained from Northwestern University Skin Disease Research Center (Chicago, IL) and cultured in keratinocyte-serum free medium (Life Technologies). A total of $5 \times 10^{5}$ $\mathrm{HaCaT}$ cells or primary keratinocytes were cultured in a 12 -well plate insert $(0.4-\mu \mathrm{m}$ pore size) for 1 to 2 days in their growth medium. The inserts were switched to E-medium and cultured for 2 weeks to make the stratified epidermis. E-medium contained 50:50 (v/v) DMEM and Ham's F-12 supplemented with $18 \mu \mathrm{mol} / \mathrm{L}$ adenine, 500 $\mathrm{ng} / \mathrm{mL}$ bovine pancreatic insulin, $500 \mathrm{ng} / \mathrm{mL}$ human apo-transferrin, $500 \mathrm{ng} / \mathrm{mL}$ triiodothyronine, $4 \mathrm{mmol} / \mathrm{L}$ L-glutamine, $0.4 \mu \mathrm{g} / \mathrm{mL}$ hydrocortisone, $10 \mathrm{ng} / \mathrm{mL}$ cholera toxin, $5 \mathrm{ng} / \mathrm{mL}$ epidermal growth factor, 5\% FBS, and antibiotics (penicillin/streptomycin). When the keratinocyte and fibroblast co-culture was performed, stratified $\mathrm{HaCaT}$ cells were placed in the upper well, and human foreskin dermal fibroblasts were placed in the bottom plates. Human foreskin fibroblasts and E-medium were purchased from Northwestern University Skin Disease Research Center.

To maintain hydration conditions, HESC and SKC were cultured in a closed chamber with a humid environment (Figure 1A). To generate increased water loss conditions (reduced hydration), HESC and SKC were cultured while exposed to dry air flow (Figure 1A). The two major S100A8/ A9 receptors, TLR4 and RAGE, were blocked by adding 400 $\mathrm{nmol} / \mathrm{L}$ TAK-242, a specific inhibitor of TLR4 (EMD Millipore, Billerica, MA), and $500 \mathrm{nmol} / \mathrm{L}$ FPS-ZM1, a specific antagonist of RAGE (EMD Millipore), to the cell culture medium.

\section{Skin Three-Dimensional Culture Using the Human Decellularized Dermis}

The human skin three-dimensional culture model was established on the basis of previous studies with some modifications. ${ }^{27}$ Briefly, human skin specimens were obtained from elective abdominoplasties. By using a dermatome, specifically a Weck knife, a partial-thickness skin specimen (approximately 10\% of full thickness) was generated and then placed in $2 \mathrm{~mol} / \mathrm{L} \mathrm{NaCl}$ solution at $37^{\circ} \mathrm{C}$ for 24 hours to completely remove the epidermis. Thereafter, the dermis was snap frozen in liquid nitrogen, followed by an immediate thaw at $37^{\circ} \mathrm{C}$. The freeze-thaw process was repeated three times. The dermal tissue was incubated in phosphate-buffered saline at $4^{\circ} \mathrm{C}$ for 3 weeks to completely remove the stromal cells in the dermis. $\mathrm{HaCaT}$ cells were then seeded onto the basement membrane of the decellularized dermal matrix set in a cell culture insert. After 2 days, the growth medium, DMEM supplemented with $10 \%$ FBS, was drained from the top of the cell culture to generate a liquid-air interface environment for the seeded keratinocytes, whereas the growth medium in the surrounding area was replaced with E-medium. HaCaT cells were fully differentiated between days 10 and 14. Hemidesmosome protein BP180- and BP230-specific antibodies (gifts from Dr. Jonathan Jones, Northwestern University Feinberg 
A

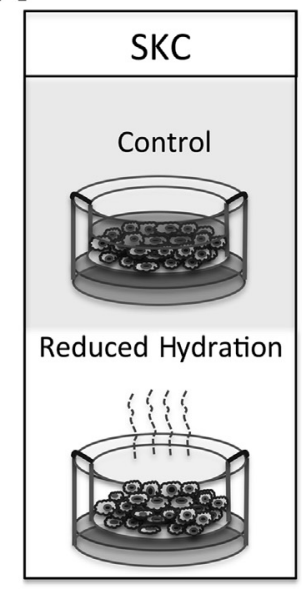

B

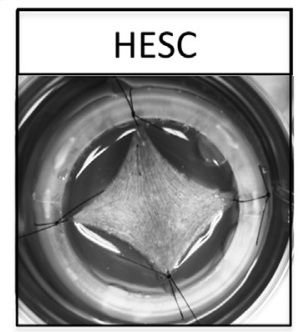

C

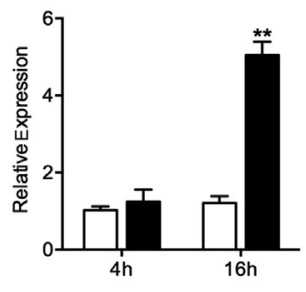

S100A9

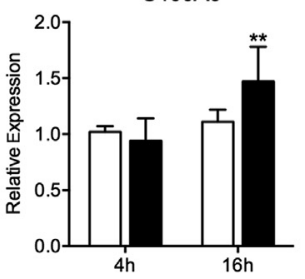

D
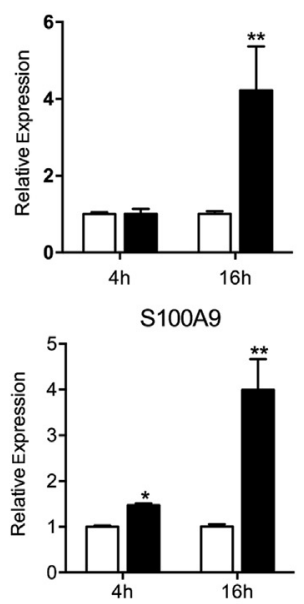

E

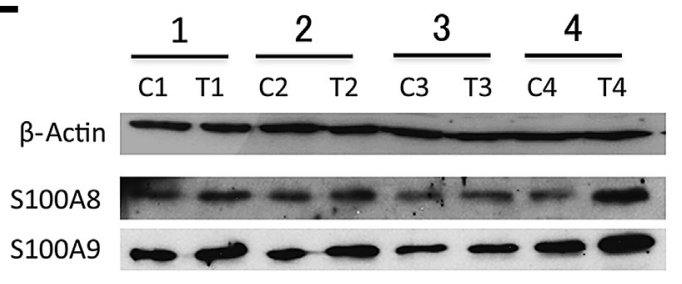

F
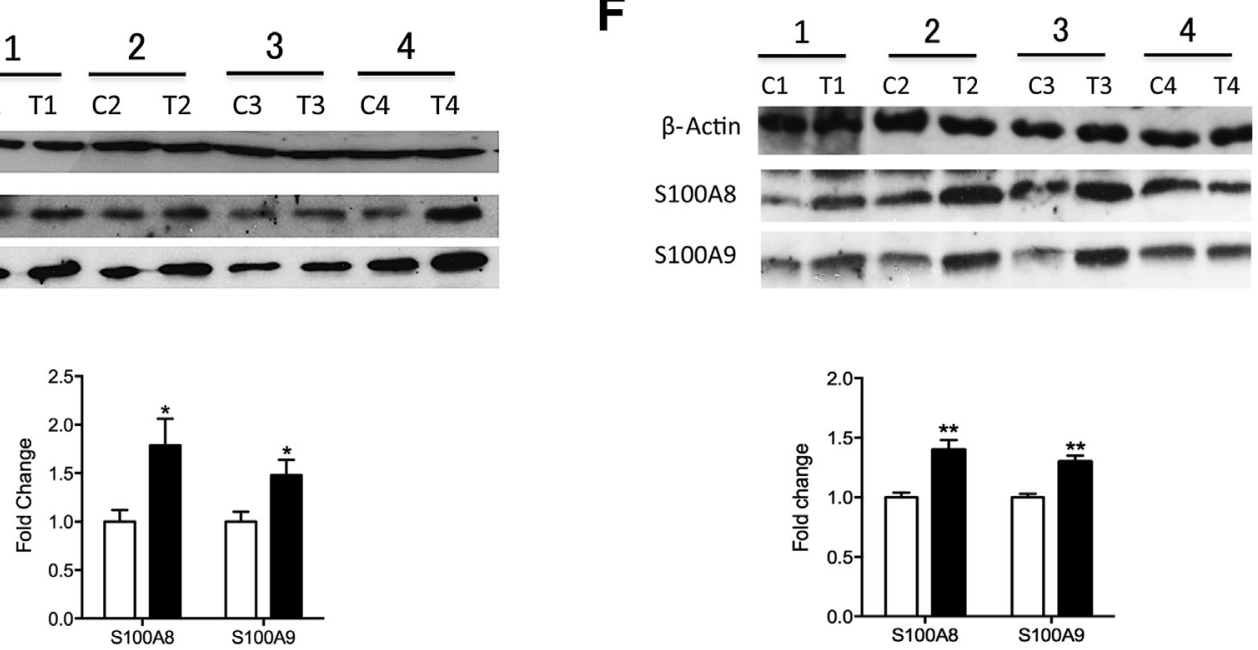

Figure 1 Reduction of hydration increases the expression of S100A8/A9 in keratinocytes. A: Schematic drawing of stratified keratinocyte culture (SKC). B: Human ex vivo skin culture (HESC). C and D: mRNA expression. SKC and HESC were treated with reduced hydration (black bars) or control conditions (white bars) for 4 and 16 hours. Total RNAs were isolated, and quantitative RT-PCR was performed. Gene expression was normalized to the expression level of glyceraldehyde-3-phosphate dehydrogenase. The level of S100A8/A9 expression in SKC (C) and HESC (D) treated with reduced hydration was compared with that in control conditions, which was set at 1. E and F: Protein expression. SKC and HESC from four patients $(1,2,3$, and 4$)$ were cultured in reduced hydration or control conditions for 16 hours. Protein $(20 \mu \mathrm{g})$ from SKC (E) and the epidermis of HESC (F) was loaded in $12 \%$ polyacrylamide gel, and the expression of S100A8/A9 protein was detected with their respective antibodies. $\beta$-Actin was detected as a loading control. The bar graphs show the quantification of the protein expression. Expression of S100A8/A9 was normalized to that of $\beta$-actin and was quantified with the NIH ImageJ program. ${ }^{*} P<0.05,{ }^{*} P<0.01 . n=4$ (C-E and $\mathbf{F}$, S100A8); $n=8(\mathbf{F}$, S100A9). C1 to C4, control condition; T1 to T4, reduced hydration treatment.

School of Medicine, Chicago, IL) were used to analyze the integrity of the epidermal basement membrane and dermal-epidermal junction. ${ }^{24}$

\section{Quantitative RT-PCR}

The epidermis of the HESC samples was separated from the dermis by treating the sample with $0.5 \mathrm{~mol} / \mathrm{L}$ ammonium thiocyanate for 30 minutes at room temperature. ${ }^{12,26,28}$ The epidermis was placed in Trizol Reagent (Sigma-Aldrich, St. Louis, MO) and homogenized using a MagNA Lyser (Roche, Indianapolis, IN) in the presence of Zirconia beads (2.0-mm diameter; Biospec Products Inc., Bartlesville, OK). Stratified or monolayer HaCaT cells were treated with Trizol Reagent alone. Total RNA was isolated according to the manufacturer's protocol. Contaminating genomic DNA during RNA preparation was removed using the Turbo DNA-free kit (Life Technologies). cDNA was made using Superscript II from $2 \mu \mathrm{g}$ of total RNA, and quantitative PCR analyses using SYBR Green I were performed using an ABI Fast Real-Time PCR System (Life Technologies). Glyceraldehyde-3-phosphate dehydrogenase was used as a normalization control, $\Delta \mathrm{Ct}$. The $2^{-\Delta \Delta \mathrm{Ct}}$ formula was used to calculate the gene expression difference between samples. Primers used for quantitative PCR are listed in Table 1. 
Table 1 Primer Pairs Used for qPCR

\begin{tabular}{|c|c|c|}
\hline Target gene & $\begin{array}{l}\text { Primer } \\
\text { type }\end{array}$ & Sequence \\
\hline \multirow[t]{2}{*}{$\overline{C X C L 8}$} & Forward & 5'-TTTTGCCAAGGAGTGCTAAAGA-3' \\
\hline & Reverse & $5^{\prime}-$ АACCCTCTGCACCCAGTTTTC-3' \\
\hline \multirow[t]{2}{*}{$I L 1 B$} & Forward & 5'-CTCGCCAGTGAAATGATGGCT-3' \\
\hline & Reverse & $5^{\prime}$-GTCGGAGATTCGTAGCTGGAT-3' \\
\hline \multirow[t]{2}{*}{ TNF } & Forward & 5'-ATGAGCACTGAAAGCATGATCC-3' \\
\hline & Reverse & $5^{\prime}$-GAGGGCTGATTAGAGAGAGGTC-3' \\
\hline \multirow[t]{2}{*}{ PTGS2 (Cox-2) } & Forward & 5'-GTGCAACACTTGAGTGGCTAT-3' \\
\hline & Reverse & 5'-AGCAATTTGCCTGGTGAATGAT-3' \\
\hline \multirow[t]{2}{*}{ S100A8 } & Forward & $5^{\prime}$-ATGCCGTCTACAGGGATGAC- $3^{\prime}$ \\
\hline & Reverse & $5^{\prime}$-ACGCCCATCTTTATCACCAG-3' \\
\hline \multirow[t]{2}{*}{ S100A9 } & Forward & $5^{\prime}$-GGTCATAGAACACATCATGGAGG-3' \\
\hline & Reverse & 5'-GGCCTGGCTTATGGTGGTG-3' \\
\hline \multirow[t]{2}{*}{ GAPDH } & Forward & 5'-TGTTGCCATCAATGACCССTT-3' \\
\hline & Reverse & $5^{\prime}$-CTCCACGACGTACTCAGCG-3' \\
\hline \multirow[t]{2}{*}{$\beta$-Actin } & Forward & $5^{\prime}$-CATGTACGTTGCTATCCAGGC-3' \\
\hline & Reverse & $5^{\prime}$-CTCCTTAATGTCACGCACGAT-3' \\
\hline
\end{tabular}

qPCR, quantitative PCR

\section{Immunostaining and Western Blot Analysis}

Slides divided into sections from paraffin-embedded tissues and fixed cell culture were used for immunostaining. For the tissues, sections (4 $\mu \mathrm{m}$ thick) were deparaffinized and treated with antigen retrieval solution (10 mmol/L sodium citrate and $0.05 \%$ Tween $20, \mathrm{pH}$ 6.0). After primary antibody treatment, fluorescencelabeled secondary antibodies were used for immunofluorescence staining. The primary antibodies used for immunostaining include S100A8 (rabbit anti-human; a gift from Dr. Philippe Tessier, Université Laval, Quebec City, QC, Canada; 1:1000 dilution), S100A9 (rabbit anti-human; a gift from Dr. Philippe Tessier; 1:1000 dilution), procollagen-I (mouse anti-human; Developmental Studies Hybridoma Bank at University of Iowa, Iowa City, IA; 1:1000 dilution), cytokeratin 14 (CK14; rabbit anti-human; Covance, Princeton, NJ; 1:5000 dilution), CK10 (mouse anti-human; Dako, Carpinteria, CA; 1:5000 dilution), and $\alpha$-smooth muscle actin ( $\alpha$-SMA; rabbit anti-human; Santa Cruz Biotechnology, Santa Cruz, CA; 1:1000 dilution).

For immunohistochemistry, biotin-conjugated secondary antibodies (Vector Laboratories, Burlingame, CA) were treated after Ki-67 (mouse anti-human; BD Biosciences, San Jose, CA; 1:1000) or caspase-3 (Cell Signaling, Beverly, MA) specific antibody treatment. The signal was detected using the Vectastain kit (Vector Laboratories) and visualized using 3,3'-diaminobenzidine.

For Western blot analysis, whole cell extracts were prepared using radioimmunoprecipitation assay buffer $(50 \mathrm{mmol} / \mathrm{L}$ Tris, $150 \mathrm{mmol} / \mathrm{L} \mathrm{NaCl}, 1 \%$ Triton $\mathrm{X}-100,0.1 \% \mathrm{SDS}$, and $0.5 \%$ sodium deoxycholate, $\mathrm{pH}$ 7.5). Trichloroacetic acid/acetone/ medium (1:8:1 volume) was used to concentrate proteins in culture medium. Proteins were separated onto SDS polyacrylamide gels and transferred onto polyvinylidene difluoridenitrocellulose membranes.

After primary antibody treatment, horseradish peroxidaseconjugated secondary antibody was applied and the signal was visualized using an Enhanced Chemiluminescence detection kit (GE Healthcare Bio-Sciences, Piscataway, NJ). $\beta$-Actin was used as a normalization control. The density of the signal was quantified by the ImageJ software version 1.46r (NIH, Bethesda, MD; http://imagej.nih.gov/ij). The primary antibodies used for immunoblot staining include S100A8 (rabbit anti-human; a gift from Dr. Philippe Tessier; 1:5000 dilution), S100A9 (rabbit anti-human; a gift from Dr. Philippe Tessier; 1:5000 dilution), $\alpha$-SMA (mouse anti-human; Santa Cruz Biotechnology; 1:1000 dilution), and $\beta$-actin (rabbit anti-human; Santa Cruz Biotechnology; 1:5000).

\section{Gene Knockdown by RNAi}

The sequences of shRNAs were selected using the RNAi consortium database. $^{29}$ The double-stranded shRNA

Table 2 Sequence for shRNA

\begin{tabular}{|c|c|c|}
\hline Target gene & Primer type & Sequence \\
\hline \multirow[t]{2}{*}{$C X C L 8^{*}$} & Forward & 5'-CCGGGCTCTGTGTGAAGGTGCAGTTCTCGAGAACTGCACCTTCACACAGAGCTTTTTG-3' \\
\hline & Reverse & 5'-ААТTСАААААGСTCTGTGTGAAGGTGCAGTTCTCGAGAACTGCACCTTCACACAGAGC-3' \\
\hline \multirow[t]{2}{*}{$I L 1 B^{*}$} & Forward & 5'-CCGGATCAATAACAAGCTGGAATTTCTCGAGAAATTCCAGCTTGTTATTGATTTTTTG-3' \\
\hline & Reverse & 5'-ААТTCAАAAАATCAATAACAAGCTGGAATTTCTCGAGAAATTCCAGCTTGTTATTGAT-3' \\
\hline \multirow[t]{2}{*}{$T N F^{*}$} & Forward & 5'-CCGGCСTСTCTСTAATCAGCCСTCTCTCGAGAGAGGGCTGATTAGAGAGAGGTTTTT-3' \\
\hline & Reverse & 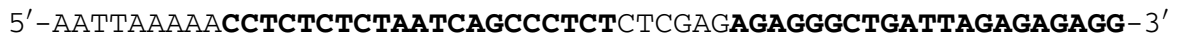 \\
\hline \multirow[t]{2}{*}{ S100A8 } & Forward & 5'-CCGGCCACAAGTACTCCCTGATAAACTCGAGTTTATCAGGGAGTACTTGTGGTTTTTG-3' \\
\hline & Reverse & 5'-ААТTCAAAAАССACAAGTACTCCCTGATAAACTCGAGTTTATCAGGGAGTACTTGTGG-3' \\
\hline \multirow[t]{2}{*}{ S100A9 } & Forward & 5'-CCGGAGAGACCATCATCAACACCTTCTCGAGAAGGTGTTGATGATGGTCTCTTTTTTG-3' \\
\hline & Reverse & 5'-ААТTCAАAAAAGAGACCATCATCAACACCTTCTCGAGAAGGTGTTGATGATGGTCTCT-3' \\
\hline
\end{tabular}

The bold sequences indicate the target sequences of RNA interference.

${ }^{*}$ Gene knockdown information described previously. ${ }^{12}$ 
Table 3 Primer Pairs Used for the Recombinant Proteins Expression

\begin{tabular}{lll}
\hline $\begin{array}{l}\text { Target } \\
\text { gene }\end{array}$ & $\begin{array}{l}\text { Primer } \\
\text { type }\end{array}$ & Sequence \\
\hline Human & Forward & $5^{\prime}$-CATATGTTGACCGAGCTGGAGAAA-3' \\
S100A8 & Reverse & $5^{\prime}$-GGATCCCTACTCTTTGTGGCTTTC-3' \\
Human & Forward & $5^{\prime}$ - CATATGACTTGCAAAATGTCGCAG-3' \\
S100A99 & Reverse & $5^{\prime}$-GGATCCTTAGGGGGTGCCCTCCCC-3' \\
Rabbit & Forward & $5^{\prime}$ - CATATGCCGACTGATCTGGAAAAT-3' \\
S100A8 & Reverse & $5^{\prime}$ - GGATCCCTACGCCTTGTGGCTGTCT- \\
& & TC-3' \\
\hline
\end{tabular}

The underlined sequences denote the restriction enzyme sites, NdeI (forward) and BamHI (reverse). The bold sequences denote the start codon (forward) and stop codon (reverse).

oligos were cloned to pLKO.1 puro vector (Addgene, Cambridge, MA), and lentiviruses were made following the protocol provided by Addgene. Lentivirus-transduced $\mathrm{HaCaT}$ cells were selected in the presence of $2 \mu \mathrm{g} / \mathrm{mL}$ puromycin. Knockdown of S100A8 or S100A9 was tested by Western blot analysis. The following double-stranded shRNA sequences were made (IDT, Coralville, IA) for RNAi of S100A8 or S100A9 (Table 2). The boldfaced sequences indicate the target sequences of RNAi for S100A8 and S100A9. RNAi information for IL-1 $\beta$, IL-8, cyclooxygenase (Cox)-2, and tumor necrosis factor (TNF)- $\alpha$ was described previously. ${ }^{12}$

\section{Recombinant Protein Preparation}

The open reading frames of human S100A8, human S100A9, and rabbit S100A8 (http://www.ncbi.nlm.nih.gov/nuccore; GenBank accession numbers NM_002964, NM_002965, and XM_002715343, respectively) genes were cloned by PCR, and their sequences were confirmed by DNA sequencing. The open reading frames of human S100A8, human S100A9, and rabbit S100A8 were cloned to pET-15b (Novagen, Madison, WI), which carries an N-terminal His Tag, using the NdeI and BamHI restriction enzyme sites, and constructed pET-hS100A8, pET-hS100A9, and pETrS100A8 (Table 3). pET-hS100A8 was transformed to Escherichia coli BL21 (DE3) strain. pET-hS100A9 and pET-rS100A8 were transformed to E. coli BL21 (DE3) pLysS strain. Induction of human S100A8 was performed by adding $1 \mathrm{mmol} / \mathrm{L}$ isopropyl $\beta$-D-1-thiogalactopyranoside for 3 hours at $37^{\circ} \mathrm{C}$. Induction of human S100A9 and rabbit S100A8 was performed by adding $1 \mathrm{mmol} / \mathrm{L}$ isopropyl $\beta$-D1-thiogalactopyranoside for 5 hours at $25^{\circ} \mathrm{C}$. His-Tagged proteins were purified using the nickel-chelating resin following the standard purification protocol. Recombinant proteins were eluted in the presence of $250 \mathrm{mmol} / \mathrm{L}$ imidazole and dialysis against phosphate-buffered saline. Recombinant proteins were further purified using the Pierce High Capacity Endotoxin Removal Resin (Life Technologies).

\section{Human Specimens}

For the HESC, human skin was obtained from elective abdominoplasties. Human tissues were acquired under a protocol approved by the Institutional Review Board of Northwestern University. For the histological analysis of S100A8 and S100A9, human normal skin, hypertrophic scar, and keloid specimens were obtained under the protocols approved by the Institutional Review Board of Northwestern University and Tongji Medical College. Human specimens were obtained from Northwestern Memorial Hospital (Chicago, IL) and Union Hospital (Wuhan, Hubei, China). A biopsy was performed on samples from chest skin of patients who underwent scar excision (10 cases of hypertrophic scar and five cases of keloid) and patients who underwent skin grafting (five cases of normal skin). The patients were 20 to 35 years old, and the lesions were excised at least 1 year after formation. Of all 20 cases, two keloid specimens were from humans of African descent and 18 were from Asian descent. Hypertrophic scars were caused by surgery, burn, or cut; however, the cause of keloids was unclear. Tissues were fixed in formalin and embedded in paraffin.

\section{Animal Experiments}

Animal experiments in this study were approved by the Northwestern University Animal Care and Use Committee. Female New Zealand white rabbits were purchased from Covance. Six excisional wounds (7 $\mathrm{mm}$ full thickness) were generated on the ventral surface of each rabbit ear. A semiocclusive dressing, Tegaderm, was placed onto the wounded ear to prevent desiccation. When the wounds were fully reepithelialized, approximately 14 days after wounding, recombinant rabbit S100A8 protein was injected into the wounds at postoperative days (PODs) 15, 19, and 23 (10 $\mu \mathrm{g}$ per wound, each time). Saline was injected into the wounds in the contralateral ear as a control. The rabbit wounds were harvested at POD 28, fixed in formalin, embedded in paraffin, and divided into sections ( $4 \mu \mathrm{m}$ thick). The histological slides were stained for hematoxylin and eosin dyes and analyzed using a Nikon Eclipse 50i light microscope (Nikon Instruments Inc., Melville, NY). The scar elevation index (SEI) was calculated. ${ }^{30,31}$

\section{MTT Assay}

Wild-type or gene knockdown $\mathrm{HaCaT}$ cells were seeded onto 48 -well plates $\left(2 \times 10^{4}\right.$ cells per well $)$ and cultured in DMEM supplemented with 10\% FBS for 24 hours. The culture was replaced with new medium $(200 \mu \mathrm{L}$ per well), and MTT reagent $(5 \mathrm{mg} / \mathrm{mL}$; Sigma-Aldrich) was added (20 $\mu \mathrm{L}$ per well). After 3 hours of incubation at $37^{\circ} \mathrm{C}$, stop solution (15\% SDS in $40 \%$ dimethylformamide) was added to the well $(200 \mu \mathrm{L}$ per well) and mixed thoroughly. After stabilization of the reaction for 2 hours, the absorbance of each well was measured at $550 \mathrm{~nm}$ in a microtiter plate reader. The absorbance at $630 \mathrm{~nm}$ was also recorded, which served as the background control. The relative viability of 

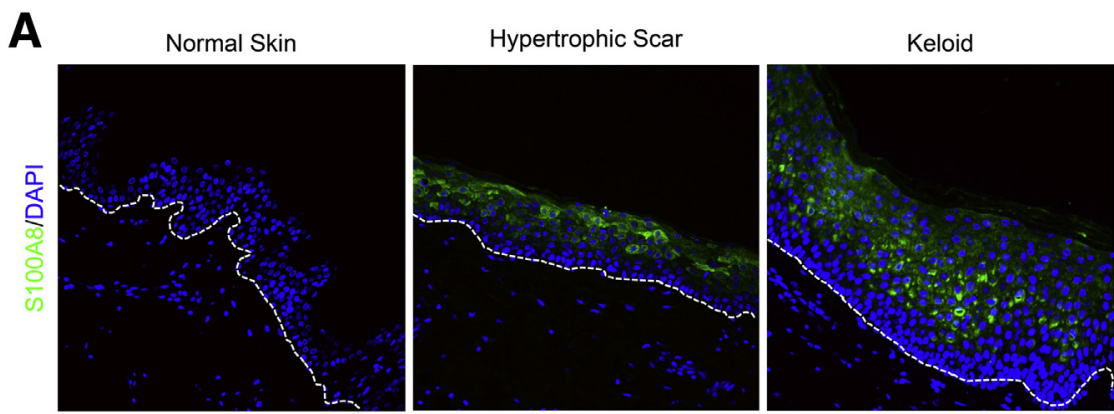

Figure 2 High expression levels of S100A8/A9 are found in human hypertrophic scar and keloid tissues. A: Normal skin was obtained from the donor site of patients for skin graft, and scar tissue was obtained from patients who underwent scar removal plastic surgery. Tissues divided into sections were stained with S100A8/ A9-specific antibodies and visualized with fluorescence-labeled secondary antibodies, green and red, respectively. Nuclei were counterstained with DAPI (blue). White lines denote the dermal-epidermal junction of the skin. B: Low magnification. Scale bars: $50 \mu \mathrm{m}(\mathbf{A}) ; 100 \mu \mathrm{m}$ (B).
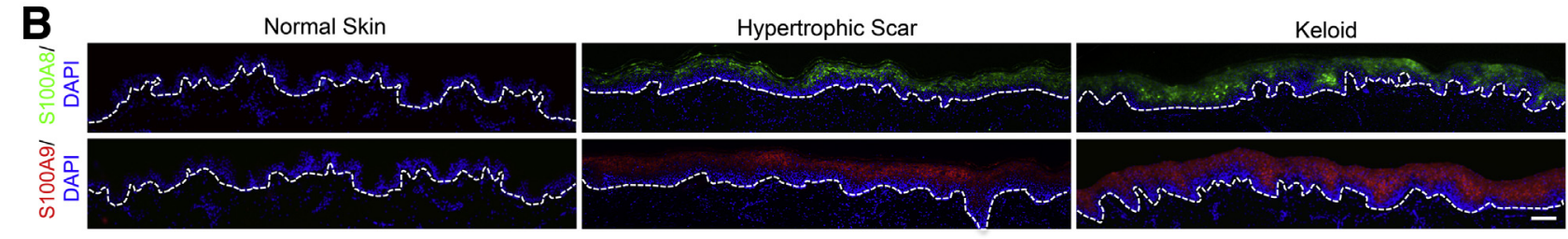

cells was calculated as the net absorbance ratio A550-A630 (test/control). The viability of control cells was set as $100 \%$.

\section{Quantification of Images and Statistical Analysis}

NIS Elements program (Nikon Instruments Inc.) was used for the analysis of rabbit ear hypertrophic scar histology. S100A8-treated and control scars were analyzed with paired $t$-test. The ImageJ program was used for the quantification of the Western blot and immunofluorescence staining. The band signals of the Western blot were translated into total intensities and used for $t$-test analysis. For immunofluorescence staining, average fluorescence per cell was calculated. Briefly, the total fluorescent density of all of the cells in each observation field was captured by ImageJ. The total number of cells in this field was counted on the basis of the staining of the nuclei. The average fluorescence per cell was calculated by dividing the total signal density/number of cells in the same observation field. This was repeated with five different observation fields. The $t$-test was applied to estimate the significance of the difference between each treatment.

\section{Results}

\section{Expression of S100A8/S100A9 Is Increased in} Epidermal Keratinocytes by Reduced Hydration

Our previous studies in the rabbit ear model showed that hydration status affects cutaneous wound healing in that preserving hydration conditions enhances wound repair in skin. ${ }^{10,12}$ In addition, global gene expression analysis using microarray showed apparent differences in gene expression between hydrated and nonhydrated wounds. Many genes involved in inflammation, including S100A8 and S100A9, were highly up-regulated in wounds that were not hydrated. We investigated whether hydration status directly regulates the expression level of S100A8 and S100A9 using the SKC and HESC (Figure 1, A and B). We placed SKC in a low humidity environment to provide reduced hydration conditions, which simulated wounds without hydration in vivo (Figure 1A). In addition, we placed SKC in a high humidity environment, which was equivalent to hydrated wounds. mRNA levels of S100A8 and S100A9 were significantly higher in SKC that were incubated for 16 hours in low humidity compared with controls (5.1- \pm 0.4 -fold versus 1.5- \pm 0.3 -fold) (Figure 1C). No significant change in S100A8 or S100A9 mRNA expression was found in SKC cultured at 4 hours with the same treatment. We investigated expression of S100A8 and S100A9 in the HESC model. ${ }^{24}$ We removed the stratum corneum, a major contributor of the barrier function of skin, using tape stripping. Both S100A8 and S100A9 mRNA expression in HESC was significantly increased in low humidity compared with controls (4.2- \pm 1.1-fold versus 4.0- \pm 0.7-fold) (Figure 1D). We further analyzed expression of S100A8 and S100A9 proteins. In line with the mRNA result, Western blot analysis showed that expression of S100A8 and S100A9 proteins in SKC was increased by 1.79- and 1.48- fold, 

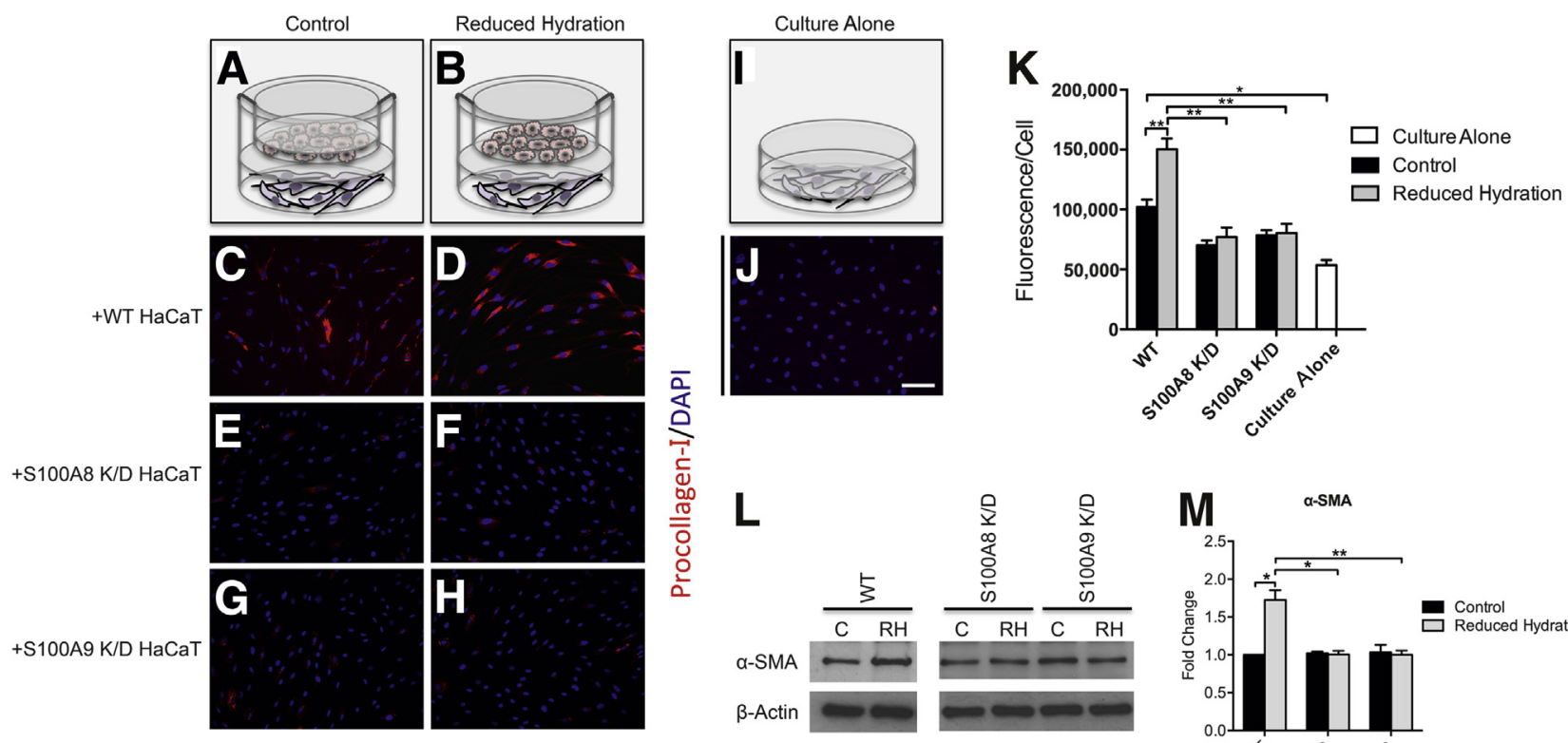

Figure 3 Reduced hydration conditions increase the expression of S100A8/A9 in keratinocytes and activate dermal fibroblasts. A and B: Stratified wild-type (WT) or S100A8/A9 knockdown (K/D) keratinocytes (HaCaT cells) in a cell culture insert were co-cultured with human foreskin fibroblasts plated in the lower chamber. $\mathbf{C}-\mathbf{H}$ : Keratinocyte-fibroblast co-culture was treated with reduced hydration (RH; D, F, and $\mathbf{H})$ or control conditions (C; C, E, and G) for 16 hours. I-J: Submerged monolayer fibroblast culture was used as a control. C $-\mathbf{H}$ and J: Procollagen-I expression. Immunofluorescence staining with procollagen-I-specific antibody was performed in fibroblasts (red). Nuclei were counterstained with DAPI (blue). K: Quantification of expression of procollagen-I by ImageJ. $\mathbf{L}$ and $\mathbf{M}$ : Expression of $\alpha$-smooth muscle actin $(\alpha-S M A)$. Western blot analysis (L) and quantification (M). Expression of S100A8/A9 was normalized to $\beta$-actin and was quantified with the NIH ImageJ program. ${ }^{*} P<0.05,{ }^{*} P<0.01 . n=3$ (K). Scale bar $=50$ $\mu \mathrm{m}(\mathbf{C}-\mathbf{H}$ and $\mathbf{J})$.

respectively, when stratified $\mathrm{HaCaT}$ cells were cultured for 16 hours in low humidity (decreased hydration conditions) compared with controls (Figure 1E). In addition, increased expression of S100A8 and S100A9 proteins in stratified primary foreskin keratinocytes was detected in low humidity (Supplemental Figure S1A). Expression of S100A8 and S100A9 protein in HESC was increased by 1.39- and 1.29-fold by the same condition (Figure 1F).

\section{S100A8 and S100A9 from Epidermal Keratinocytes Activate Dermal Fibroblasts in Skin}

Increased expression of proinflammatory cytokines from the epidermis causes dermal fibroblast activation, which is often found in pathological scars, such as hypertrophic scars and keloids. ${ }^{3,32}$ We hypothesize that sustained expression of S100A8 and S100A9, which have cytokine functions, in epidermal keratinocytes is one of the causes of skin fibrosis. We investigated whether the expression of S100A8 and S100A9 was up-regulated in human pathological scar tissues. We analyzed hypertrophic scar and keloid tissues from 10 and 5 patients, respectively. Immunostaining showed that S100A8 and S100A9 were highly expressed in both hypertrophic scar and keloid tissue, whereas their expression was rarely detected in normal skin (Figure 2). The signals of S100A8 and S100A9 were distributed in the suprabasal layer of the epidermis.
Next, we addressed whether S100A8 (and S100A9) from the epidermis activates dermal fibroblasts. By using the transwell plate system, we cultured human foreskin fibroblasts in the bottom well plate and keratinocytes in the upper well plate (Figure 3, A and B). To simulate the epidermis structure of skin, we stratified $\mathrm{HaCaT}$ cells. Expression of procollagen-I, which is an activation marker of fibroblasts, was increased in fibroblasts when stratified $\mathrm{HaCaT}$ cells were exposed to dry air (low humidity/reduced hydration) compared with the control, where stratified $\mathrm{HaCaT}$ cells were cultured in the submerged condition (maintained hydration) (Figure 3, C versus D and K). When we generated the S100A8 and S100A9 knockdown by lentivirus-mediated RNAi (Supplemental Figure S1, B and C), the up-regulation of procollagen-I seen in reduced hydration conditions was abolished (Figure 3, E versus F and Figure 3, G versus H). When monolayer fibroblasts alone were cultured without keratinocytes (Figure 3I), moderate to weak expression of procollagen-I was detected (Figure 3J). We further verified the dependence of dermal fibroblast activation on the hydration status of epidermal keratinocytes by analyzing another activation marker of fibroblast, $\alpha$-SMA, in fibroblasts. Western blot analysis showed that the 1.7-fold increased expression of $\alpha$-SMA in fibroblasts, observed in reduced hydration, was abolished by the knockdown of S100A8 or S100A9 in HaCaT cells (Figure 3, L and M). In this transwell plate system, expression of procollagen-I in 

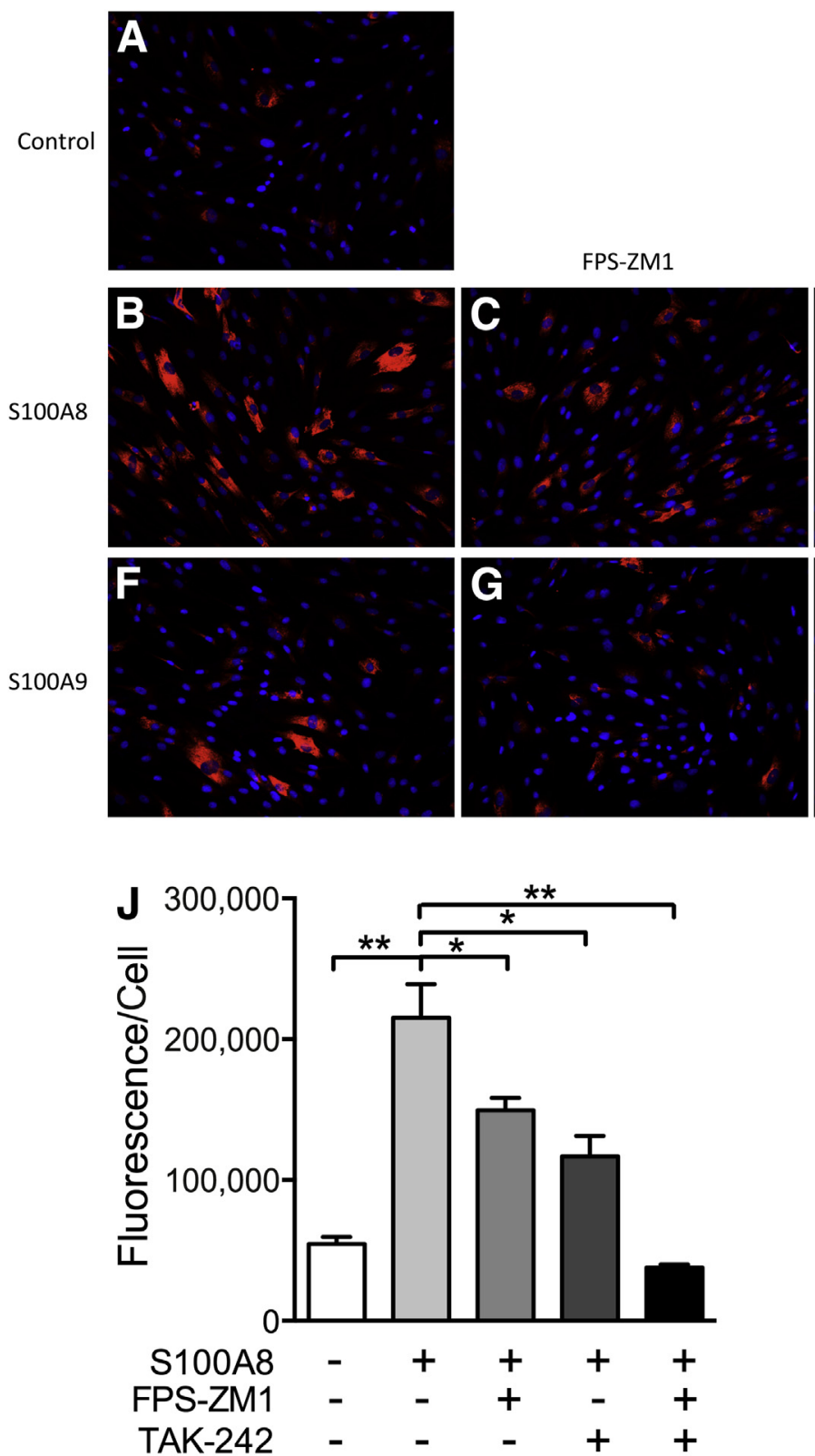

TAK-242
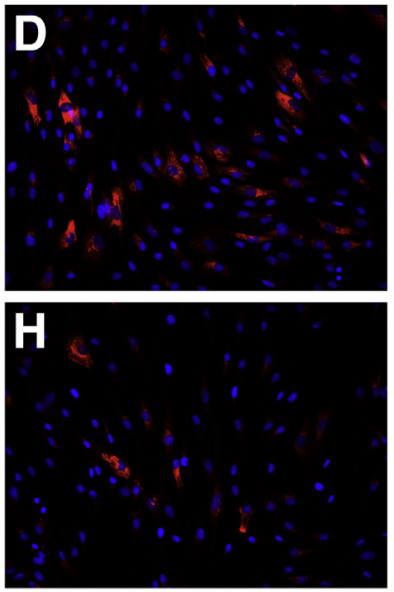

FPS-ZM1+TAK-242
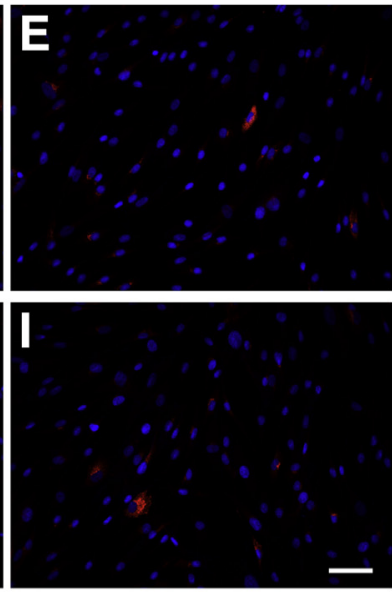

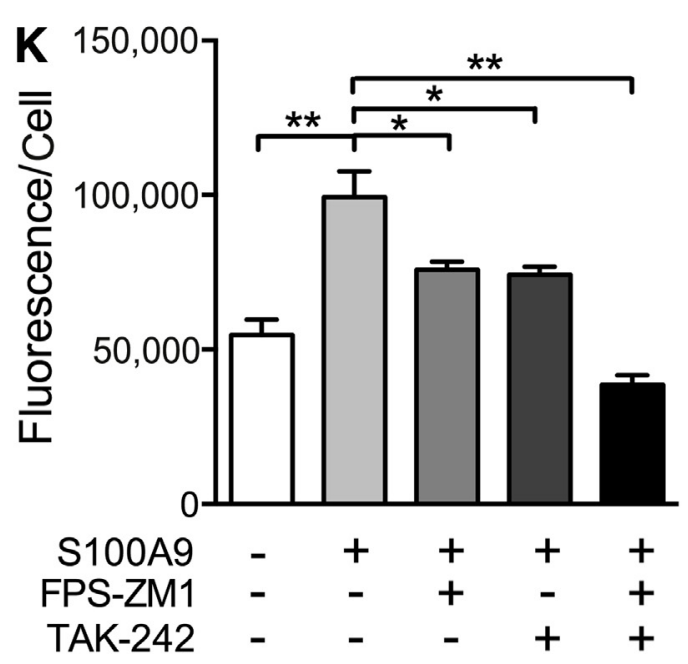

Figure 4 S100A8/A9-activated human foreskin fibroblasts through Toll-like receptor (TLR) 4 and receptor for advanced glycation end products (RAGE). Purified recombinant human S100A8 or S100A9 protein was added at $1 \mu \mathrm{g} / \mathrm{mL}$ into culture medium of foreskin fibroblasts in the presence or absence of 400 $\mathrm{nmol} / \mathrm{L}$ TAK-242 or $500 \mathrm{nmol} / \mathrm{L}$ FPS-ZM1, TLR4-specific, or RAGE-specific inhibitors, respectively. After 16 hours, fibroblasts were analyzed for the expression of procollagen-I. A-I: Fibroblasts were stained using procollagen-I-specific antibody and visualized with fluorescence-labeled secondary antibody (red). A: Fibroblasts without recombinant protein treatment were used as a control. $\mathbf{J}$ and K: Quantification of the expression of procollagen-I by S100A8 (J) and S100A9 (K) treatment using the NIH ImageJ program. Signals from fibroblasts without recombinant protein treatment were set as $1 .{ }^{*} P<0.05,{ }^{* *} P<0.01$. $n=5$. Scale bar $=50 \mu \mathrm{m}(\mathbf{A}-\mathbf{I})$.

fibroblasts was affected by soluble factors produced by $\mathrm{HaCaT}$ cells because fibroblasts were separated from the $\mathrm{HaCaT}$ cells. These data suggest that S100A8 and S100A9 play a critical role in the interaction between keratinocytes and fibroblasts. To support this notion, the presence of S100A8/A9 protein in the culture medium of stratified $\mathrm{HaCaT}$ cells was detected (Supplemental Figure S1D).

We hypothesized that S100A8 and S100A9 proteins, which were up-regulated and secreted from keratinocytes in response to reduced hydration conditions, migrate into the dermis and activate dermal fibroblasts. We used reconstituted HESCs to localize S100A8 and S100A9 proteins secreted from keratinocytes. We seeded and stratified $\mathrm{HaCaT}$ cells on top of the basal membrane of decellularized dermis, which maintains the dermal-epidermal junction (Supplemental Figure S2). We placed the reconstituted HESCs in the reduced hydration conditions and cultured for 16 hours (Supplemental Figure S3, A, B, E, and F). Increased expression of S100A8 and S100A9 was found in the stratified keratinocytes (Supplemental Figure S3, G and H). 

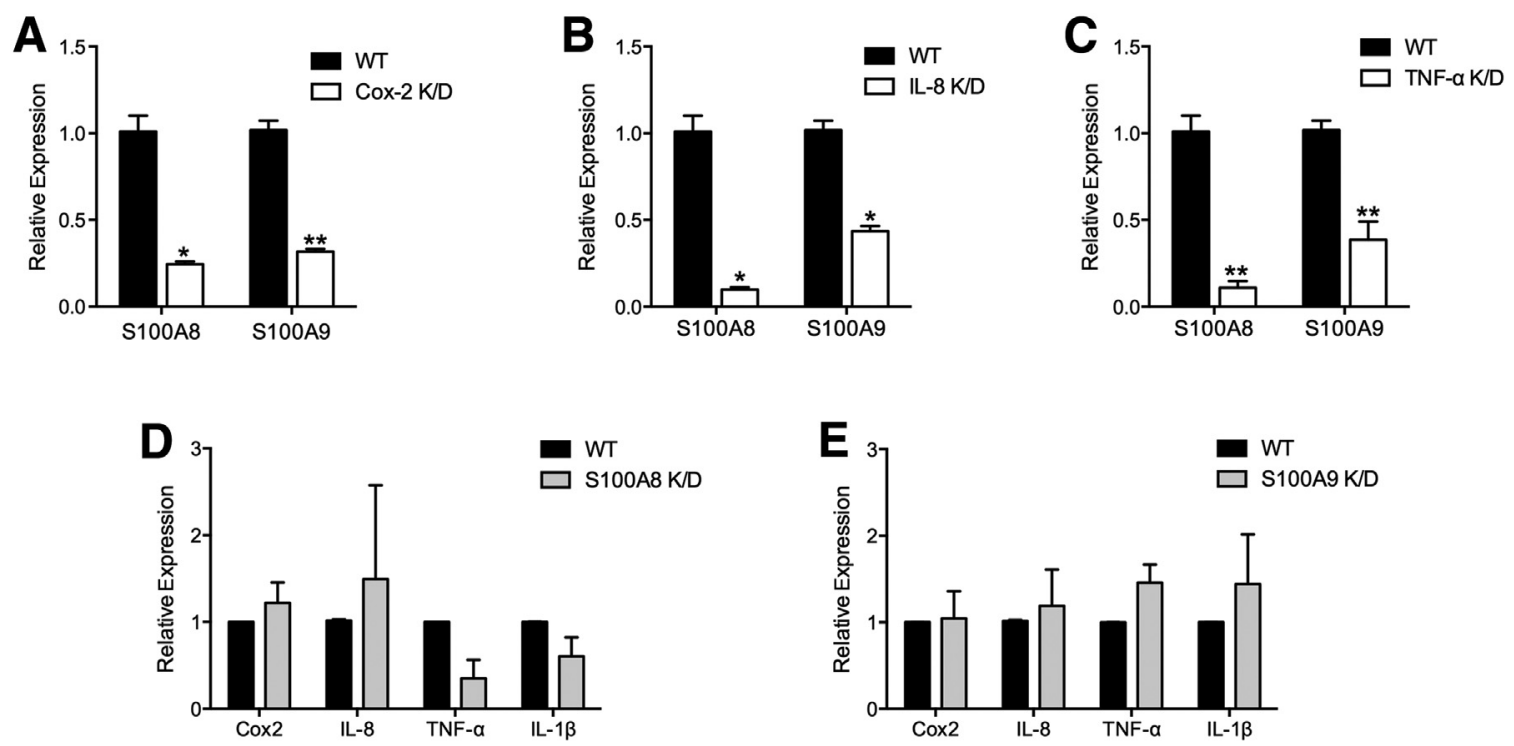

Figure 5 Hierarchical relationship between S100A8/A9 and other proinflammatory genes that were up-regulated by the hydration conditions. Lentivirusmediated RNA interference was used to generate cyclooxygenase 2 (Cox-2), IL-8, and tumor necrosis factor (TNF)- $\alpha$ knockdown HaCaT cells. Wild-type (WT) and gene knockdown (K/D) HaCaT cells were stratified and treated with reduced hydration or control conditions for 16 hours. mRNA expression in HaCaT cells was measured by quantitative RT-PCR. A-C: The level of S100A8/A9 in Cox-2 (A), IL-8 (B), and TNF- $\alpha$ (C) K/D HaCaT cells was compared with that of the WT, which was set as 1. D and E: The level of Cox-2, IL-8, and TNF- $\alpha$ in S100A8 (D) and S100A9 (E) K/D HaCaT cells was compared with that of the WT. ${ }^{*} P<0.05$, ${ }^{*} P<0.01 . n=4(\mathbf{A}-\mathbf{E})$.

In addition, we analyzed the signal below the keratinocytes in the decellularized dermis, where no cells exist, as a control. No signal was detected when decellularized matrix was cultured alone (Supplemental Figure S3, C and D). Western blot analysis further confirmed the migration of S100A8 and S100A9 from the epidermis to the dermis (Supplemental Figure S3I).

\section{S100A8 and S100A9 Activate Fibroblasts through Both TLR4 and RAGE}

It is known that S100A8 and S100A9 are highly upregulated on wounding in skin and function as cytokines secreted from epidermal keratinocytes. Cytokines secreted from cells bind to their specific receptors in the target cells to perform their roles. It is known that the S100 family proteins bind to RAGE ${ }^{33,34}$ and, more recently, TLR4. ${ }^{35,36}$ We investigated how secreted S100A8 and S100A9 activate dermal fibroblasts. We used human recombinant S100A8 and S100A9 proteins that were expressed and purified from E. coli (Supplemental Figure S4). We observed that treatment of S100A8 or S100A9 protein at 1 $\mu \mathrm{g} / \mathrm{mL}$ in the culture medium for 16 hours increased expression of procollagen-I and $\alpha$-SMA in dermal fibroblasts that were cultured in monolayer (Figure 4, A-C and F, and Supplemental Figure S5). This activation was diminished when either TLR4 or RAGE was treated with its specific blocker, TAK-242 or FPS-ZM1, respectively (Figure 4, C, D, G, H, J, and K). When both receptors were blocked, the expression level of procollagen-I decreased to basal levels, as shown in the control, where no recombinant protein was treated (Figure 4, E, I, J, and K). These data clearly indicate that S100A8 and S100A9 activate dermal fibroblasts through both TLR4 and RAGE.

\section{Hierarchical Regulation of Inflammatory Genes in Keratinocytes}

Our previous microarray study showed that the expression of many proinflammatory genes, including $I L 1 B, I L 8, T N F A$, and PTGS2, was elevated in the wounded epidermis where hydration was not maintained. ${ }^{12} \mathrm{We}$ also showed that in keratinocytes, $I L I B$ is an up-stream regulator of $I L 8$ in response to changes in hydration status. It is known that hierarchical regulation of genes depends on environment. For example, although IL- $1 \beta$ regulates S100A8 in mouse endothelial and fibroblast cells, ${ }^{37,38}$ IL- $1 \beta$ is regulated by S100A8 in human alveolar epithelial cells and mouse bone marrow-derived macrophages. ${ }^{16}$ Thus, we addressed the hierarchical relation of S100A8/A9 with IL1B,IL8,TNFA, and $P T G S 2$ in keratinocytes using RNAi-mediated gene knockdown. Wild-type and gene knockdown HaCaT cells were stratified and treated with reduced hydration or control conditions for 16 hours, and gene expression was quantified by quantitative RT-PCR. The expression level of S100A8 was decreased by $76 \%, 90 \%$, and $89 \%$ in the PTGS2, IL8, and TNFA knockdown HaCaT cells, respectively (Figure 5, A-C). The expression of S100A9 was decreased by $68 \%$, $56 \%$, and $61 \%$ in the Cox-2, IL- 8 , and TNF- $\alpha$ knockdown $\mathrm{HaCaT}$ cells, respectively (Figure 5, A-C). Although expression of IL-1 $\beta$ was increased in S100A8 or S100A9 knockdown $\mathrm{HaCaT}$ cells, it was not statistically significant 


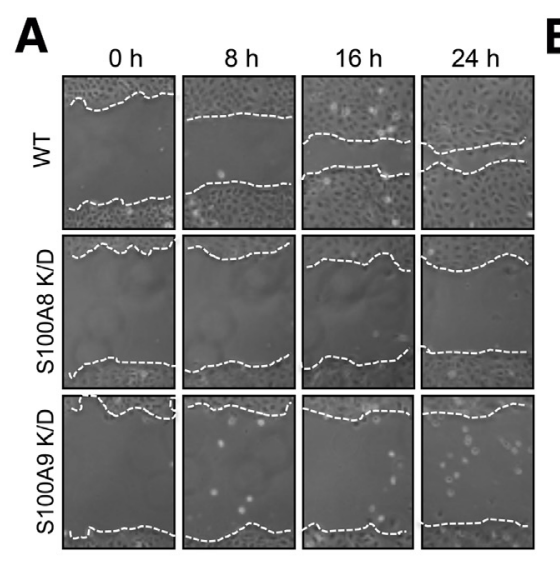

WT

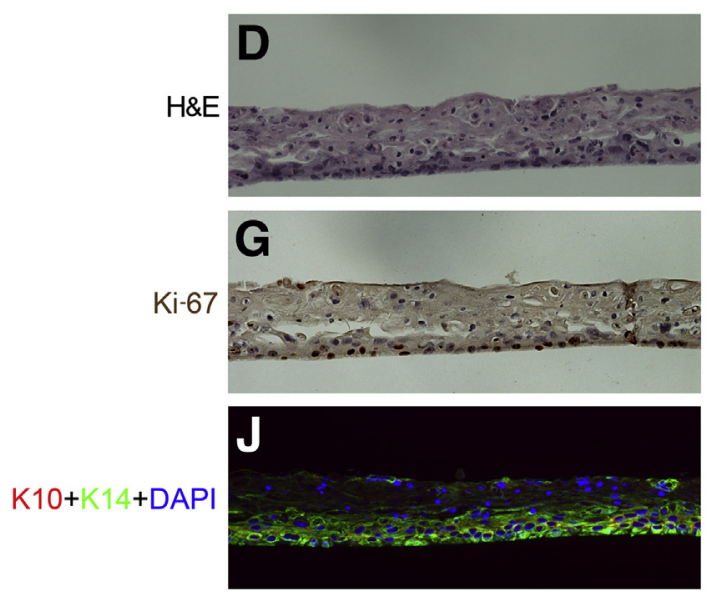

B

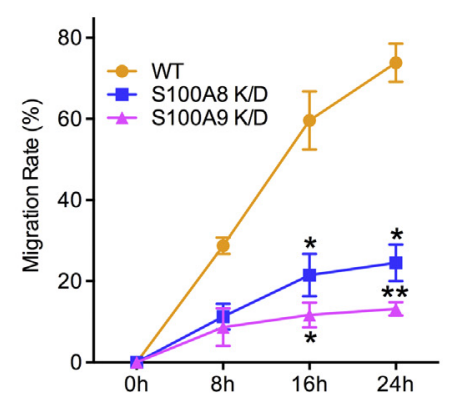

C

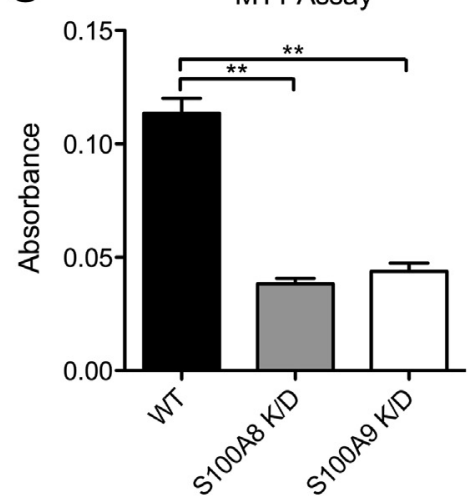

S100A9 K/D
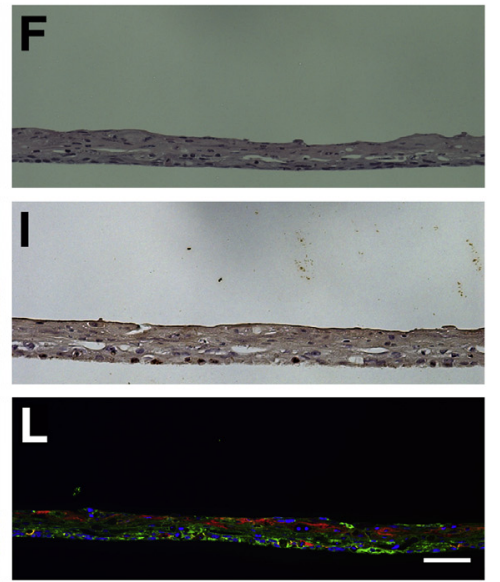

Figure 6 Knockdown (K/D) of S100A8/A9 affects the migration and differentiation of keratinocytes. A: Analysis of cell migration using in vitro scratch assay. Migration of S100A8 or S100A9 K/D and wild-type (WT) HaCaT cells was measured at 0, 8, 16, and 24 hours after generating scratch wounds. B: Quantification of migration. Migration rate was calculated by measuring the cell migrated area/original wound area. C: MTT assay. WT and S100A8 or S100A9 K/D HaCaT cells were cultured for 24 hours, and MTT assay was performed. D-L: WT and S100A8 or S100A9 K/D HaCaT cells were stratified in vitro for 2 weeks. D-F: Hematoxylin and eosin (H\&E) staining. G-I: Ki-67 staining. Proliferating cells were detected using Ki-67-specific antibody. Dark brown color indicates Ki-67-positive signal. Nuclei were stained with hematoxylin. J-L: Immunofluorescence staining. Expression of cytokeratin 10 (red) and 14 (green) was detected with their respective antibodies. Nuclei were stained with DAPI. ${ }^{*} P<0.05,{ }^{*} P<0.01 . n=3(\mathbf{B}$ and $\mathbf{C})$. Scale bar $=50 \mu \mathrm{m}(\mathbf{D}-\mathbf{L})$.

(data not shown). Next, we addressed whether S100A8 and S100A9 regulate expression of other proinflammatory genes. Knockdown of S100A8 did not affect expression of IL-1 $\beta$, IL8, and Cox-2. Expression of TNF- $\alpha$ was reduced in S100A8 knockdown $\mathrm{HaCaT}$ cells but was not statistically significant (Figure 5D). Expression of IL-1 $\beta$, IL-8, TNF- $\alpha$, and Cox-2 was not affected by S100A9 knockdown (Figure 5E). These gene knockdown studies suggest that S100A8 and S100A9 are downstream of TNFA, IL8, and PTGS2.

\section{Knockdown of S100A8 and S100A9 Affects Keratinocyte Migration and Proliferation}

We addressed whether knockdown of S100A8 and S100A9 affects the migration and proliferation of keratinocytes. In vitro scratch assay showed that cell migration was significantly delayed in S100A8 and S100A9 knockdown HaCaT cells compared with wild type (Figure 6, A and B).
MTT assays showed that proliferation of $\mathrm{HaCaT}$ cells was drastically reduced by knockdown of $S 100 A 8$ or $S 100 A 9$ in $\mathrm{HaCaT}$ cells (Figure 6C). Then, we examined differentiation of S100A8 or S100A9 knockdown HaCaT cells. Stratification of wild-type and S100A8 knockdown HaCaT cells showed multiple layers (Figure 6, D and E). In contrast, S100A9 knockdown HaCaT cells showed fewer layers of stratification (Figure 6F). Proliferating cells, which were detected by Ki-67 staining, were found mostly in the basal layer of the stratified keratinocytes (Figure 6, G-I). The number of Ki-67-positive cells was decreased in S100A8 and S100A9 knockdown stratified HaCaT cells compared with wild type. Although it had fewer layers, stratified S100A9 knockdown HaCaT cells expressed keratinocyte differentiation markers, CK14 and CK10, in the basal and suprabasal layers, respectively, as shown in wild type (Figure 6, J and L). The expression of CK10 was reduced in stratified S100A8 knockdown HaCaT cells (Figure 6K). 

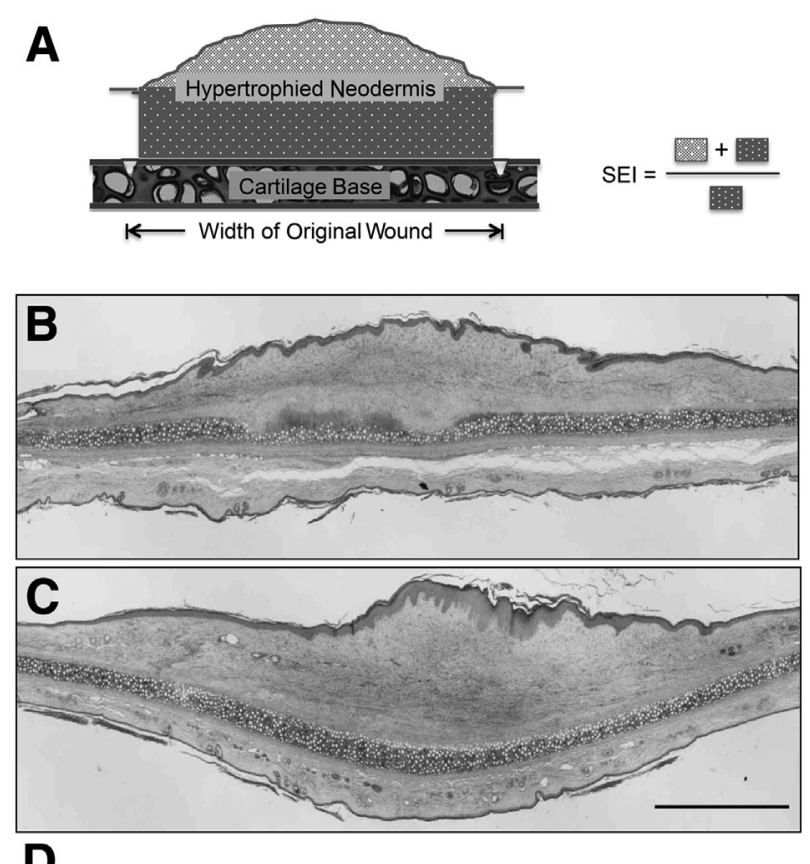

D

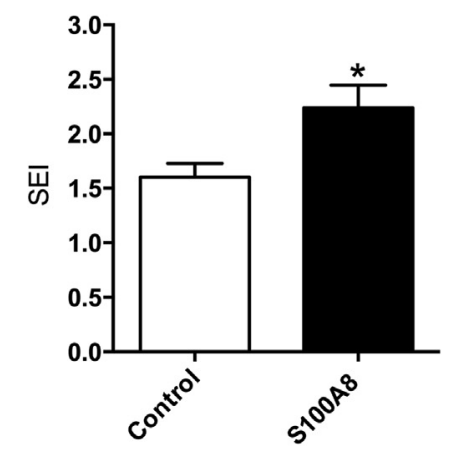

Figure 7 Exogenous S100A8 treatment increases scar hypertrophy in the rabbit ear model. Full-thickness $7-\mathrm{mm}$ excision wounds were made on the ventral surface of the rabbit ears at day 0 . Purified recombinant rabbit S100A8 protein was injected into the surrounding tissue of wounds at postoperative days (PODs) 15, 19, and 23. Wounds were harvested at POD 28, and histological analysis was performed. A: The scar elevation index (SEI) measurement. The SEI is a ratio of area of newly formed dermis (total scar area)/estimated area of non-scarred dermis (unwounded dermis). An SEI of 1 indicates that the wound healed with no scar hypertrophy, and an SEI $>1$ represents a raised hypertrophic scar. B and C: Representative images of scar tissues with hematoxylin and eosin (H\&E) staining at POD 28. Saline (B) and S100A8 (C) injected rabbit ear wounds are shown. D: SEI. Twelve wounds for S100A8 treatment and 12 saline controls were used for the analysis. ${ }^{*} P<0.05$. Scale bar $=100 \mu \mathrm{m}$ (B and $\left.\mathbf{C}\right)$.

\section{Exogenous S100A8 Protein Treatment Increases Scar Hypertrophy}

Sustained activation of dermal fibroblasts, which deposit excessive collagen in the dermis, is one of the underlying mechanisms of hypertrophic scar. ${ }^{39,40}$ Our in vitro data showed that S100A8/A9 activates dermal fibroblasts (Figures 3 and 4). Furthermore, higher expression of S100A8 and S100A9 was found in human pathological scars we investigated (Figure 2). Thus, we hypothesized that up-regulated S100A8/A9 in the epidermis by the reduced hydration conditions induces dermal fibrosis. We performed a gain-of-function study using the wellvalidated hypertrophic scar model in the rabbit ear. ${ }^{8,9,26}$ In this model, scar hypertrophy can be quantified by measuring SEI (Figure 7A). We chose to administer S100A8 protein because it showed higher up-regulation in the reduced hydration conditions compared with S100A9 (Figure 1, C, E, and F). We delivered $10 \mu \mathrm{g}$ of recombinant rabbit S100A8 per wound at multiple time points: PODs 15, 19, and 23. We delivered vehicle alone to control wounds located on the contralateral ear. When analyzed at POD 28, wounds injected with S100A8 protein showed higher scar hypertrophy (SEI, $2.24 \pm 0.20$ ) compared with the controls (SEI, $1.60 \pm 0.12$ ) (Figure 7, $\mathrm{B}-\mathrm{D})$.

\section{Discussion}

Silicone gel has been widely used in the clinical setting for the management of hypertrophic scars and keloids. ${ }^{7,8}$ Although the signaling pathway involved in this process is not fully understood, it is thought that occlusion with silicone restores the barrier function of skin, increases the hydration status of the epidermis, and further reduces fibrosis in the dermis. We previously showed that topical silicone gel treatment decreases TEWL and hypertrophic scarring in the rabbit ear model. ${ }^{8}$ Removing the stratum corneum, the major component of the skin barrier function, increased TEWL and hypertrophic scarring. Furthermore, occlusion reduced profibrotic gene expression, such as $I L 1 B$, in the epidermis. ${ }^{9}$ Mucosal wounds, which maintain hydration, have shown less inflammation with faster healing and minimal scarring compared with cutaneous wounds. Global gene expression analysis has also shown that expression of many proinflammatory genes was downregulated in mucosal wounds. ${ }^{10,11}$ Recently, we directly showed that proinflammatory gene expression in the epidermis is regulated by hydration status. ${ }^{12}$ We found that expression of S100A8/A9 was up-regulated in wounds under reduced hydration conditions. ${ }^{12}$

Although S100A8/A9 are constitutively expressed in myeloid cells, they show minimal expression in normal skin. However, wounding in the skin increased the expression of S100A8/A9 in the epidermis. ${ }^{21}$ Furthermore, overexpression of S100A8 or S100A9 was found in lesional skin of psoriasis patients ${ }^{23,41}$ and nonhealing wounds. ${ }^{22}$ Our analysis showed that S100A8/A9 were highly up-regulated in hypertrophic scars and keloids (Figure 2). Evidence indicates that increased TEWL promotes inflammation-triggering dermal fibrosis by secreting various profibrotic factors. ${ }^{33,34} \mathrm{We}$ showed that S100A8/A9 are novel profibrotic factors that activate dermal fibrosis in the study.

Secreted S100A8/A9 are known to bind receptors, RAGE and TLR4. RAGE is a member of the immunoglobulin superfamily of cell surface receptors and binds to multiple ligands, such as AGEs and high-mobility group protein B1. ${ }^{42,43}$ RAGE is involved in cystic fibrosis, myocardial 
fibrosis, and hepatic cirrhosis. TLR4 belongs to a highly conserved receptor family and binds to multiple ligands, such as lipopolysaccharide and high-mobility group protein B1. ${ }^{44}$ TLR4 is involved in the host immune response to bacterial infection and many aseptic inflammatory diseases of the cardiovascular, pulmonary, and hepatic systems. ${ }^{33,45}$ Interestingly, S100A8/A9 can bind to both RAGE and TLR4, which share many ligands and downstream signaling pathways. ${ }^{43,46}$ We showed that both RAGE and TLR4 are receptors of S100A8/A9 in fibroblasts through use of their specific blockers (Figure 4).

Hierarchical regulation of proinflammatory cytokines has been reported in cells. Treatment of proinflammatory cytokines, such as TNF- $\alpha$, IL- $1 \beta$, IL- 6 , and prostaglandin $E_{2}$, up-regulated expression of S100A8 or S100A9 in various cells, such as endothelial cells, macrophages, and keratinocytes. ${ }^{37,38,47-49}$ In the opposite way, S100A8 or S100A9 treatment up-regulated expression of IL-8 and TNF- $\alpha$ in many cells, such as endothelial cells, melanoma cells, bone marrow cells, alveolar epithelial cells, and macrophages. ${ }^{16,50}$ Our hierarchical analysis using RNAi showed that PTGS2, IL8, and TNFA are upstream of S100A8/A9 in keratinocytes (Figure 5).

The wound healing process of research animals is different from that of humans. ${ }^{51}$ Open wounds in rodents heal quickly secondary to wound contraction. This is different from human skin wounds that heal to a significant degree by regeneration of new tissue via granulation tissue and reepithelialization. Porcine models have been used in wound healing because of their anatomical similarity to human skin. ${ }^{52}$ However, the scar is entirely flat and does not visually appear hypertrophic. The rabbit ear hypertrophic scar model has several parameters that behave in a similar manner to human hypertrophic scars. ${ }^{9,53,54}$ The model allows sensitive, reproducible quantification of hypertrophic scarring. The scars develop by 28 days after injury and closely resemble human hypertrophic scars in appearance, histology, and inflammation within the scar. The rabbit ear hypertrophic scar model shares with human scars a similar response to both clinical therapeutics (including steroids and a variety of occlusive dressings) and multiple investigational therapies (including inhibitors of collagen synthesis and transforming growth factor- $\beta$ ). One of the limits of rabbits is variation between different animals because they are not syngeneic. Thus, in this study, each animal had its own control: S100A8 treatment (one ear) and vehicle treatment (contralateral ear). We previously showed that timing of applications of therapeutics is important to achieve the wanted effect. ${ }^{54}$ We started to deliver S100A8 protein in this study for the gain-of-function study at POD 15 when epithelialization was complete, and the healing response reflects the initiation of scar development and remodeling (Figure 7).

Our hypothesis was that skin barrier function disruption up-regulates proinflammatory cytokines in the epidermis and further induces fibrosis in the dermis. Blocking IL-1 signaling, one of the up-regulated proinflammatory cytokines, using an IL-1 receptor antagonist, effectively prevented hypertrophic scar formation in the rabbit ear model.$^{10}$ Recently, we demonstrated that reduced hydration in the epidermis causes sodium flux, monitored through the epithelial sodium channel, and up-regulated downstream inflammatory pathways. ${ }^{26}$ Blocking the epithelial sodium channel or its downstream gene, PTGS2 (encoding for COX-2), resulted in remarkable reduction of scarring in the rabbit ear model. ${ }^{26}$ These data suggest that inhibition or blockage of the proinflammatory pathway in response to barrier function disruption of the skin is a promising strategy for scar management. Herein, we showed that S100A8/A9, which are downstream of COX-2, TNF- $\alpha$, and IL-8, are important players in skin hypertrophic scar formation. Our results indicate that TEWL promotes fibroblast activation and fibrosis by directly affecting expression of inflammatory signaling in keratinocytes. We suggest that S100A8/A9 are novel targets for the prevention of dermal fibrosis.

\section{Acknowledgments}

We thank Dr. Philippe Tessier (Université Laval, Quebec City, QC, Canada) for the S100A8 and S100A9 antibodies, Dr. Jonathan Jones (Northwestern University Feinberg School of Medicine, Chicago, IL) for BP180- and BP230-specific antibodies, and Dr. Soleil Leilabadi and Gabriel Arenas for the critical review of the manuscript.

\section{Supplemental Data}

Supplemental material for this article can be found at http://dx.doi.org/10.1016/j.ajpath.2015.09.005.

\section{References}

1. Ueha S, Shand FH, Matsushima K: Cellular and molecular mechanisms of chronic inflammation-associated organ fibrosis. Front Immunol 2012, 3:71

2. Wynn TA: Common and unique mechanisms regulate fibrosis in various fibroproliferative diseases. J Clin Invest 2007, 117:524-529

3. Bellemare J, Roberge CJ, Bergeron D, Lopez-Valle CA, Roy M, Moulin VJ: Epidermis promotes dermal fibrosis: role in the pathogenesis of hypertrophic scars. J Pathol 2005, 206:1-8

4. Machesney M, Tidman N, Waseem A, Kirby L, Leigh I: Activated keratinocytes in the epidermis of hypertrophic scars. Am J Pathol 1998, 152:1133-1141

5. Tandara AA, Mustoe TA: The role of the epidermis in the control of scarring: evidence for mechanism of action for silicone gel. J Plast Reconstr Aesthet Surg 2008, 61:1219-1225

6. Suetake T, Sasai S, Zhen YX, Ohi T, Tagami H: Functional analyses of the stratum corneum in scars: sequential studies after injury and comparison among keloids, hypertrophic scars, and atrophic scars. Arch Dermatol 1996, 132:1453-1458

7. Mustoe TA: Evolution of silicone therapy and mechanism of action in scar management. Aesthetic Plast Surg 2008, 32:82-92

8. O’Shaughnessy KD, De La Garza M, Roy NK, Mustoe TA: Homeostasis of the epidermal barrier layer: a theory of how occlusion 
reduces hypertrophic scarring. Wound Repair Regen 2009, 17: 700-708

9. Gallant-Behm CL, Mustoe TA: Occlusion regulates epidermal cytokine production and inhibits scar formation. Wound Repair Regen 2010, 18:235-244

10. Gallant-Behm CL, Du P, Lin SM, Marucha PT, DiPietro LA, Mustoe TA: Epithelial regulation of mesenchymal tissue behavior. J Invest Dermatol 2011, 131:892-899

11. Chen L, Arbieva ZH, Guo S, Marucha PT, Mustoe TA, DiPietro LA: Positional differences in the wound transcriptome of skin and oral mucosa. BMC Genomics 2010, 11:471

12. Xu W, Jia S, Xie P, Zhong A, Galiano RD, Mustoe TA, Hong SJ: The expression of proinflammatory genes in epidermal keratinocytes is regulated by hydration status. J Invest Dermatol 2014, 134: 1044-1055

13. Eckert RL, Broome AM, Ruse M, Robinson N, Ryan D, Lee K: S100 proteins in the epidermis. J Invest Dermatol 2004, 123:23-33

14. Vogl T, Gharibyan AL, Morozova-Roche LA: Pro-inflammatory S100A8 and S100A9 proteins: self-assembly into multifunctional native and amyloid complexes. Int J Mol Sci 2012, 13:2893-2917

15. Korndorfer IP, Brueckner F, Skerra A: The crystal structure of the human (S100A8/S100A9)2 heterotetramer, calprotectin, illustrates how conformational changes of interacting alpha-helices can determine specific association of two EF-hand proteins. J Mol Biol 2007, 370:887-898

16. Vogl T, Tenbrock K, Ludwig S, Leukert N, Ehrhardt C, van Zoelen MA, Nacken W, Foell D, van der Poll T, Sorg C, Roth J: Mrp8 and Mrp14 are endogenous activators of Toll-like receptor 4, promoting lethal, endotoxin-induced shock. Nat Med 2007, 13: 1042-1049

17. van Lent PL, Grevers L, Blom AB, Sloetjes A, Mort JS, Vog1 T, Nacken W, van den Berg WB, Roth J: Myeloid-related proteins S100A8/S100A9 regulate joint inflammation and cartilage destruction during antigen-induced arthritis. Ann Rheum Dis 2008, 67: $1750-1758$

18. Foell D, Wittkowski H, Vogl T, Roth J: S100 proteins expressed in phagocytes: a novel group of damage-associated molecular pattern molecules. J Leukoc Biol 2007, 81:28-37

19. Sorenson BS, Khammanivong A, Guenther BD, Ross KF, Herzberg MC: IL-1 receptor regulates S100A8/A9-dependent keratinocyte resistance to bacterial invasion. Mucosal Immunol 2012, 5: $66-75$

20. Abtin A, Eckhart L, Glaser R, Gmeiner R, Mildner M, Tschachler E: The antimicrobial heterodimer S100A8/S100A9 (calprotectin) is upregulated by bacterial flagellin in human epidermal keratinocytes. J Invest Dermatol 2010, 130:2423-2430

21. Thorey IS, Roth J, Regenbogen J, Halle JP, Bittner M, Vogl T, Kaesler S, Bugnon P, Reitmaier B, Durka S, Graf A, Wockner M, Rieger N, Konstantinow A, Wolf E, Goppelt A, Werner S: The $\mathrm{Ca} 2+$-binding proteins S100A8 and S100A9 are encoded by novel injury-regulated genes. J Biol Chem 2001, 276:35818-35825

22. Eming SA, Koch M, Krieger A, Brachvogel B, Kreft S, BrucknerTuderman L, Krieg T, Shannon JD, Fox JW: Differential proteomic analysis distinguishes tissue repair biomarker signatures in wound exudates obtained from normal healing and chronic wounds. J Proteome Res 2010, 9:4758-4766

23. Madsen P, Rasmussen HH, Leffers H, Honore B, Celis JE: Molecular cloning and expression of a novel keratinocyte protein (psoriasis-associated fatty acid-binding protein [PA-FABP]) that is highly up-regulated in psoriatic skin and that shares similarity to fatty acid-binding proteins. J Invest Dermatol 1992, 99:299-305

24. Xu W, Jong Hong S, Jia S, Zhao Y, Galiano RD, Mustoe TA: Application of a partial-thickness human ex vivo skin culture model in cutaneous wound healing study. Lab Invest 2012, 92:584-599

25. Tandara AA, Kloeters O, Mogford JE, Mustoe TA: Hydrated keratinocytes reduce collagen synthesis by fibroblasts via paracrine mechanisms. Wound Repair Regen 2007, 15:497-504
26. Xu W, Hong SJ, Zeitchek M, Cooper G, Jia S, Xie P, Qureshi HA, Zhong A, Porterfield MD, Galiano RD, Surmeier DJ, Mustoe TA: Hydration status regulates sodium flux and inflammatory pathways through epithelial sodium channel $(\mathrm{ENaC})$ in skin. J Invest Dermatol 2015, 135:796-806

27. Ridky TW, Chow JM, Wong DJ, Khavari PA: Invasive threedimensional organotypic neoplasia from multiple normal human epithelia. Nat Med 2010, 16:1450-1455

28. Trost A, Bauer JW, Lanschutzer C, Laimer M, Emberger M, Hintner H, Onder K: Rapid, high-quality and epidermal-specific isolation of RNA from human skin. Exp Dermatol 2007, 16:185-190

29. Moffat J, Grueneberg DA, Yang X, Kim SY, Kloepfer AM, Hinkle G, Piqani B, Eisenhaure TM, Luo B, Grenier JK, Carpenter AE, Foo SY, Stewart SA, Stockwell BR, Hacohen N, Hahn WC, Lander ES, Sabatini DM, Root DE: A lentiviral RNAi library for human and mouse genes applied to an arrayed viral highcontent screen. Cell 2006, 124:1283-1298

30. Reid RR, Roy N, Mogford JE, Zimmerman H, Lee C, Mustoe TA: Reduction of hypertrophic scar via retroviral delivery of a dominant negative TGF-beta receptor II. J Plast Reconstr Aesthet Surg 2007, 60:64-72

31. Saulis AS, Chao JD, Telser A, Mogford JE, Mustoe TA: Silicone occlusive treatment of hypertrophic scar in the rabbit model. Aesthet Surg J 2002, 22:147-153

32. Niessen FB, Andriessen MP, Schalkwijk J, Visser L, Timens W: Keratinocyte-derived growth factors play a role in the formation of hypertrophic scars. J Pathol 2001, 194:207-216

33. Yammani RR: $\mathrm{S} 100$ proteins in cartilage: role in arthritis. Biochim Biophys Acta 2012, 1822:600-606

34. Ghavami S, Chitayat S, Hashemi M, Eshraghi M, Chazin WJ, Halayko AJ, Kerkhoff C: S100A8/A9: a Janus-faced molecule in cancer therapy and tumorgenesis. Eur J Pharmacol 2009, 625:73-83

35. Leclerc E, Heizmann CW: The importance of $\mathrm{Ca} 2+/ \mathrm{Zn} 2+$ signaling S100 proteins and RAGE in translational medicine. Front Biosci (Schol Ed) 2011, 3:1232-1262

36. Goyette J, Geczy CL: Inflammation-associated S100 proteins: new mechanisms that regulate function. Amino Acids 2011, 41: $821-842$

37. Yen T, Harrison CA, Devery JM, Leong S, Iismaa SE, Yoshimura T, Geczy CL: Induction of the S100 chemotactic protein, CP-10, in murine microvascular endothelial cells by proinflammatory stimuli. Blood 1997, 90:4812-4821

38. Rahimi F, Hsu K, Endoh Y, Geczy CL: FGF-2, IL-1beta and TGFbeta regulate fibroblast expression of S100A8. FEBS J 2005, 272 : $2811-2827$

39. Mustoe TA, Gurjala A: The role of the epidermis and the mechanism of action of occlusive dressings in scarring. Wound Repair Regen 2011, 19 Suppl 1:s16-s21

40. Wang J, Hori K, Ding J, Huang Y, Kwan P, Ladak A, Tredget EE: Toll-like receptors expressed by dermal fibroblasts contribute to hypertrophic scarring. J Cell Physiol 2011, 226:1265-1273

41. Zenz R, Eferl R, Kenner L, Florin L, Hummerich L, Mehic D, Scheuch H, Angel P, Tschachler E, Wagner EF: Psoriasis-like skin disease and arthritis caused by inducible epidermal deletion of Jun proteins. Nature 2005, 437:369-375

42. Xie J, Mendez JD, Mendez-Valenzuela V, Aguilar-Hernandez MM: Cellular signalling of the receptor for advanced glycation end products (RAGE). Cell Signal 2013, 25:2185-2197

43. Sakaguchi M, Murata H, Yamamoto K, Ono T, Sakaguchi Y, Motoyama A, Hibino T, Kataoka K, Huh NH: TIRAP, an adaptor protein for TLR2/4, transduces a signal from RAGE phosphorylated upon ligand binding. PLoS One 2011, 6:e23132

44. O'Neill LA, Golenbock D, Bowie AG: The history of Toll-like receptors: redefining innate immunity. Nat Rev Immunol 2013, 13: 453-460

45. Brechard S, Plancon S, Tschirhart EJ: New insights into the regulation of neutrophil NADPH oxidase activity in the phagosome: a focus 
on the role of lipid and $\mathrm{Ca}(2+)$ signaling. Antioxid Redox Signal 2013, 18:661-676

46. Ibrahim ZA, Armour CL, Phipps S, Sukkar MB: RAGE and TLRs: relatives, friends or neighbours? Mol Immunol 2013, 56:739-744

47. Banno T, Gazel A, Blumenberg M: Pathway-specific profiling identifies the NF-kappa B-dependent tumor necrosis factor alpharegulated genes in epidermal keratinocytes. J Biol Chem 2005, 280: 18973-18980

48. Lee MJ, Lee JK, Choi JW, Lee CS, Sim JH, Cho CH, Lee KH, Cho IH, Chung MH, Kim HR, Ye SK: Interleukin-6 induces S100A9 expression in colonic epithelial cells through STAT3 activation in experimental ulcerative colitis. PLoS One 2012, 7:e38801

49. Miao L, Grebhardt S, Shi J, Peipe I, Zhang J, Mayer D: Prostaglandin E2 stimulates S100A8 expression by activating protein kinase A and CCAAT/enhancer-binding-protein-beta in prostate cancer cells. Int J Biochem Cell Biol 2012, 44:1919-1928

50. Viemann D, Strey A, Janning A, Jurk K, Klimmek K, Vogl T, Hirono K, Ichida F, Foell D, Kehrel B, Gerke V, Sorg C, Roth J:
Myeloid-related proteins 8 and 14 induce a specific inflammatory response in human microvascular endothelial cells. Blood 2005, 105: 2955-2962

51. Ramos ML, Gragnani A, Ferreira LM: Is there an ideal animal model to study hypertrophic scarring? J Burn Care Res 2008, 29: 363-368

52. Zhu KQ, Carrougher GJ, Gibran NS, Isik FF, Engrav LH: Review of the female Duroc/Yorkshire pig model of human fibroproliferative scarring. Wound Repair Regen 2007, 15 Suppl $1:$ S32-S39

53. Kloeters O, Tandara A, Mustoe TA: Hypertrophic scar model in the rabbit ear: a reproducible model for studying scar tissue behavior with new observations on silicone gel sheeting for scar reduction. Wound Repair Regen 2007, 15 Suppl 1:S40-S45

54. Lu L, Saulis AS, Liu WR, Roy NK, Chao JD, Ledbetter S, Mustoe TA: The temporal effects of anti-TGF-beta1, 2, and 3 monoclonal antibody on wound healing and hypertrophic scar formation. J Am Coll Surg 2005, 201:391-397 